\title{
Fukushima Daiichi Accident Study Information Portal Quality Assurance Review: Pre-Public Release
}

January 2012

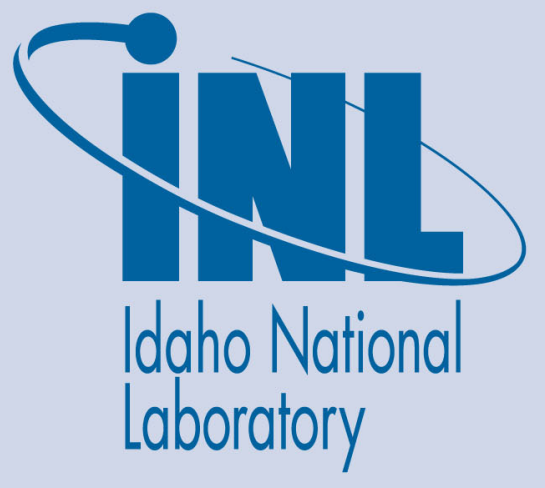

The INL is a U.S. Department of Energy National Laboratory operated by Battelle Energy Alliance 
INL/EXT-12-24576

\title{
Fukushima Daiichi Accident Study Information Portal Quality Assurance Review: Pre-Public Release
}

January 2012

\author{
Idaho National Laboratory \\ Idaho Falls, Idaho 83415
}

http://www.inl.gov 


\begin{tabular}{|c|ll|}
\hline \multicolumn{2}{|l|}{ Page: 1 of 2} \\
\hline $\begin{array}{c}\text { Software Acceptance Test Plan } \\
\text { for the Fukushima Daiichi } \\
\text { Accident Database }\end{array}$ & Identifier: & INL/EXT-12-24576 \\
\hline
\end{tabular}

\section{REVISION LOG}

$\begin{array}{cccc}\begin{array}{c}\text { Revision } \\ \text { Number }\end{array} & \begin{array}{c}\text { Effective } \\ \text { Date }\end{array} & \begin{array}{c}\text { Affected } \\ \text { Pages }\end{array} & \begin{array}{l}\text { Description of Change } \\ 0\end{array} \\ 01 / 18 / 12 & 0 & \text { Initial issue }\end{array}$




\begin{tabular}{|c|ll|}
\hline \multicolumn{2}{|l|}{ Pdaho National Laboratory } & Page: 2 of 2 \\
\hline $\begin{array}{c}\text { Software Acceptance Test Plan } \\
\text { for the Fukushima Daiichi } \\
\text { Accident Database }\end{array}$ & Identifier: & INL/EXT-12-24576 \\
\hline
\end{tabular}

\section{CONTENTS}

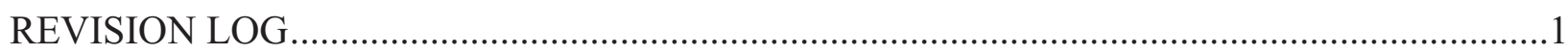

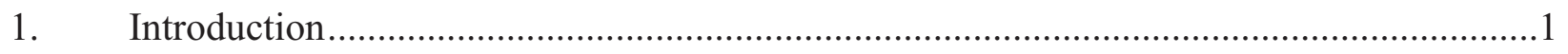

1.1 Project Background and Objectives..........................................................

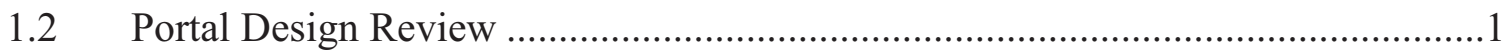

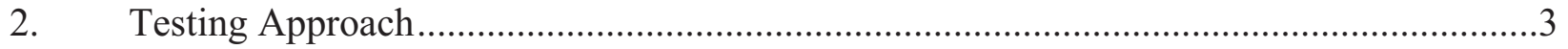

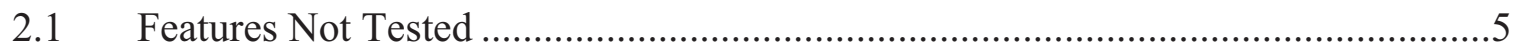

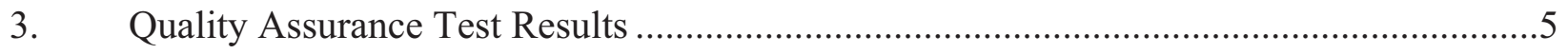

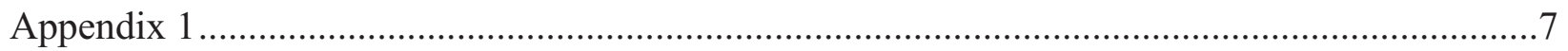




\begin{tabular}{|c|ll|}
\hline \multicolumn{2}{|l|}{ Pdaho National Laboratory 1 of 13} \\
\hline $\begin{array}{c}\text { Software Acceptance Test Plan } \\
\text { for the Fukushima Daiichi } \\
\text { Accident Database }\end{array}$ & Identifier: & INL/EXT-12-24576 \\
\hline
\end{tabular}

\section{Introduction}

\subsection{Project Background and Objectives}

The accident at the Fukushima Daiichi nuclear power station in Japan is one of the most serious in commercial nuclear power plant operating history. Much will be learned that may be applicable to the U.S. reactor fleet, nuclear fuel cycle facilities, and supporting systems, and the international reactor fleet. For example, lessons from Fukushima Daiichi may be applied to emergency response planning, reactor operator training, accident scenario modeling, human factors engineering, radiation protection, and accident mitigation; as well as influence U.S. policies towards the nuclear fuel cycle including power generation, and spent fuel storage, reprocessing, and disposal.

The NRC and DOE NE have agreed to jointly sponsor an accident reconstruction study as a means of assessing severe accident modeling capability. The lead NRC office will be the Office of Nuclear Regulatory Research and the lead DOE NE office will be the Office of Nuclear Reactor Technologies. The study team will include subject matter experts from:

Idaho National Laboratory (INL)

Oak Ridge National Laboratory (ORNL)

Sandia National Laboratory (SNL)

The overall effort will be led by SNL. This joint study is conducted under the authority of the Memorandum of Understanding between the U.S. NRC and U.S. DOE on Cooperative Nuclear Safety Research, dated April 22, 2009.

This study may serve to inform subsequent work to identify and recommend areas of improvement applicable to the safety of U.S. nuclear power plants and DOE nuclear facilities, e.g., research activities and adequacy of research-related capabilities such as ability to model and predict accident progression, radionuclide release, transport and atmospheric dispersion, enhancements to training and qualification programs (people), current hardware or future designs (parts or systems, subsystems, and components), or adequacy of operating procedures and severe accident management actions.

The Software Quality Assurance (SQA) member will provide oversight of documents relating to the Fukushima Daiichi Accident Database release management and quality, including the Acceptance Test Plan, QA Plan, and the System Test Plan.

\subsection{Portal Design Review}

This design review compared the current product with the original intent set forth in the initial internet portal design found in the document: Fukushima Daiichi Database Design, Revision 5. The current revision of the Fukushima Daiichi Accident Study Information Portal (FDASIP) is 1.0.21. This revision is one that restricts access for each user based on roles granted by the 


\begin{tabular}{|c|ll|}
\hline \multicolumn{2}{|l|}{ Page: 2 of 13} \\
\hline $\begin{array}{c}\text { Software Acceptance Test Plan } \\
\text { for the Fukushima Daiichi } \\
\text { Accident Database }\end{array}$ & Identifier: & INL/EXT-12-24576 \\
Revision: & 0 \\
Effective Date: & January 18, 2012 \\
\hline
\end{tabular}

project administrator. The public access revision is currently on the test server and will be considered in this review as well.

\subsubsection{Portal User Roles Security and Access Privileges}

The original design document identified the roles and access privileges of a contributor and an implied administrator. The contributor was defined as given privileges to add events and artifacts, associate artifacts to events and to also have editing privileges to remove associations, artifacts, etc... Other roles were developed as the portal development team undertook the project. These roles were defined in the online user's manual that was attached to the program, which has been used to update the design specifications.

The "contributor" role has not changed since the original design specification document. Three other roles were added since the original design specification: the administrator, reviewer, user, and public roles.

The "administrator" role was implied as necessary in the design specification since the portal is managed as a limited access system of information and organization. An administrator is required to grant access to the different roles at the very least. Some additional capabilities were added to the administrator's capabilities with a website statistics tab that includes user activities. There are database tool to download a data spreadsheet into the database. This became necessary to simplify addition of material from a myriad of sources. A version update tool is there for the designer under the administrator tab as well. A very nice feature not originally in the design is the report generator that is in the administrator tab. A pdf report is generated at any time that encompasses all the timelines for each unit, the events and artifacts, charts, links to reference documents in the database and more. The report comprehensively organizes and presents the portal information. This report can be viewed by contributors and others.

The "reviewer" role was added to separate contributors from those deemed capable to review the accuracy of reports; a more limited pool of experts. Reviewers can assign confidence levels of $\mathrm{Hi}$, Medium or Low. The review function serves as an information validity level assignment.

A "user" role was added to allow those with security access beyond the general public to view all the information on the site, but not allow access to contribute or review information posted to the site.

Finally, a "public" role will allow access that will open up information to the site to anyone who visits without a login. This contains the majority of the information on the site and will free up administration activities formerly required to assign roles to grant public authorization on a request by request basis.

Multiple roles can be assigned to a single portal user. Privileges are cumulative and are accessed through a single login identity and password. 


\begin{tabular}{|c|ll|}
\hline \multicolumn{2}{|l|}{ Page: 3 of 13} \\
\hline $\begin{array}{c}\text { Softwo National Laboratory } \\
\text { for the Fukushima Daiichi } \\
\text { Accident Database }\end{array}$ & Identifier: & INL/EXT-12-24576 \\
& Revision: & 0 \\
Effective Date: & January 18, 2012 \\
\hline
\end{tabular}

\subsubsection{Portal Database Design Features}

The original design document identified the features of events, artifacts, causes and reviews. The attributes assigned to these functions included the contributor, pertinent dates and times relating both to the events and artifacts along with the addition or editing in the portal database, times, and other identifying remarks.

The basic structure outlined in the database design document has remained intact from its original concept and all features identified there are implemented.

\subsubsection{Portal Utility Features}

Events, artifacts, and reviews entry and editing are implemented as per the design specification.

Utilities were added as a result of the ongoing design team development effort. A charting utility was added along with a report utility. The charting utility is currently in a static mode with the possibility of adding a dynamic mode in a future release. The functionality tested for the static mode was added to the testing plan and reviewed for the current release. The chart options available are a bar timeline component state chart and a scatter plot parameter data chart.

The report utility in the Administration tab along with its view function available to all users in the Views tab consolidates the timelines, events and artifacts into one comprehensive report. This was added to the software test plan and tested.

Timelines were described briefly in the design specification and added as an html linked view menu in the portal. They are also set up in the report. Their navigation features were added to the test plan.

\section{Testing Approach}

The test approach used for the Fukushima Daiichi Accident Database for new releases during the developmental and operational phase of the product life-cycle is based upon a "touch all buttons" methodology. The nature of the application is a database repository and a web based portal application. Automated tests are not considered necessary for this application due to a lack of calculations performed for testing to quantify acceptance. Instead, manual tests will be performed to ensure the functionality requirements of the users. A checklist of the functions will be used to ensure compliance.

The following items have been identified and tested by the designers and the SQA and have been deemed functional for release 1.0.21:

- Contributor Creation

- Artifact Creation 


\begin{tabular}{l|ll}
$\begin{array}{c}\text { Software Acceptance Test Plan } \\
\text { for the Fukushima Daiichi } \\
\text { Accident Database }\end{array}$ & Identifier: & INL/EXT-12-24576 \\
Revision: & Effective Date: January 18, 2012
\end{tabular}

○ Media file links

- Video

- Spreadsheet

- Image

- Word document

- Text

- Parameter Data

- Component State

- Event Creation

- Review Creation

○ Review Artifact

- Review Event

- Timeline View

○ Navigation

- Login Functions

- Forgotten Password

- Chart Creation

- Component State Chart

- Parameter Data Chart

- Report Creation

- Items included, events, artifacts, charts

○ Organization

- Report View

- Security

- Navigation of non-public information outside login not allowed

- Public access does not include copyrighted or controlled information

- Administrative Functions

- Add contributor

○ Modify roles

- Home Page Quick Navigation 


\begin{tabular}{|c|ll|}
\hline \multicolumn{2}{|l|}{ Pdaho National Laboratory 5 of 13} \\
\hline $\begin{array}{c}\text { Software Acceptance Test Plan } \\
\text { for the Fukushima Daiichi } \\
\text { Accident Database }\end{array}$ & Identifier: & INL/EXT-12-24576 \\
& Revision: & 0 \\
Effective Date: & January 18, 2012 \\
\hline
\end{tabular}

○ Timeline

○ Recent additions

Manual exercise of the portal was used to test the above functions and all tests have passed.

\subsection{Features Not Tested}

Like most software-development projects, time and budget constraints prohibit exhaustive testing. The verification effort focuses on the major functions of the portal. For example, the tests performed do not verify use with every browser available to public use.

\section{Quality Assurance Test Results}

Interaction between the SQA and the development team was on a spot-check basis prior to an official quality assurance test was performed on release 1.0.22. The checklist for this exercise is presented in Appendix 1, Table 1. Issues found during this test included the following:

- The current date and time is kept behind the scenes as Greenwich Mean Time (GMT). The time is then translated to local time for the user to use. A problem arose that if the application sat idle for 20 minutes, it would revert all time to GMT.

○ This was addressed in release 1.0 .23 by not automatically logging out a session that is idle for 20 minutes, which is a standard web-application operating procedure.

- When entering a time span for certain functions in the application, such as the component state charting function, there are options for using the canned radio button selected time spans or the time span can be set manually by a calendar and clock pop-up. The problem was that a radio button was left active on the canned time spans so there was no indication of what time span was being selected when manually set.

- This was addressed in release 1.0 .23 by adding a Set Manually button to the radio button field.

- Parameters are created without associating them to an event. When viewed, they are listed if they have times. If the parameter is not yet associated to an event it doesn't have a time assigned to it. Therefore, the possibility of duplicating parameters exists.

- In release 1.0.23 a prominent note in red was placed on the parameter creation screen to alert the user that parameters do not have date/time information until associated with an event.

- Units in the parameter graphing y-axis, such as "miles" for length, would cause the numbering to show as all zeroes. The opposite case also caused display problems, such as "mm" causing the number display to cut off. There was some discussion as to the usefulness of the availability of very large units such as "miles" and "km", however, it is part of the graphing utility and a solution for the display problem was found. 
Software Acceptance Test Plan for the Fukushima Daiichi Accident Database
Identifier: INL/EXT-12-24576

Revision: $\quad 0$

Effective Date: January 18, 2012

○ In release 1.0.23 the numbers display across all selections.

Another test was performed on release 1.0.23 to verify the resolution of issues found and to see if any other issues were created. The test passed all categories. 


\section{Software Acceptance Test Plan for the Fukushima Daiichi Accident Database}

$\begin{array}{ll}\text { Identifier: } & \text { INL/EXT-12-24576 } \\ \text { Revision: } & 0 \\ \text { Effective Date: } & \text { January 18, 2012 }\end{array}$

\section{Appendix 1}

Test checklist table and results of the two Quality Assurance reviews prior to public release:

Table 1 Quality Assurance test performed on version 1.0.22

\begin{tabular}{|c|c|c|c|}
\hline \multicolumn{4}{|c|}{ Test of Fukushima Daiichi Accident Study Information Portal Revision 1.0.22 } \\
\hline Item & Pass/Fail & Comment/Corrective Action & Image \\
\hline Contributor Creation & Pass & & \\
\hline Artifact Creation & Pass & & \\
\hline media file links & Pass & & \\
\hline video & Pass & & \\
\hline spreadsheet & Pass & & \\
\hline image & Pass & & \\
\hline word document & Pass & & \\
\hline text & Pass & & \\
\hline pdf document & Pass & & \\
\hline Parameter data & Fail & $\begin{array}{l}\text { It is not clear to the user if a } \\
\text { parameter is associated to an } \\
\text { event. }\end{array}$ & $\begin{array}{c}\text { Repair } \\
\text { noted in } \\
\text { Appx. } 1 \\
\text { Fig. } 4\end{array}$ \\
\hline Component state & Pass & & \\
\hline Event Creation & Pass & & \\
\hline Review Creation & Pass & & \\
\hline Review Artifact & Pass & & \\
\hline Review Event & Pass & & \\
\hline Timeline View & Fail & $\begin{array}{l}\text { Timeline span not intuitive } \\
\text { between manual entry and } \\
\text { radio buttons. Can be mis- } \\
\text { read that the active radio } \\
\text { button is controlling the time } \\
\text { span when the manual set } \\
\text { points over-ride the radio } \\
\text { button. }\end{array}$ & \\
\hline Navigation & Pass & & \\
\hline Login Functions & Pass & & \\
\hline Forgotten Password & Pass & & \\
\hline Chart Creation & Pass & & \\
\hline Component State Chart & Fail & $\begin{array}{l}\text { Timeline span not intuitive } \\
\text { between manual entry and } \\
\text { radio buttons. Can be mis- } \\
\text { read that the active radio } \\
\text { button is controlling the time } \\
\text { span when the manual set } \\
\text { points over-ride the radio } \\
\text { button. }\end{array}$ & $\begin{array}{c}\text { Appx. } 1 \\
\text { Fig. } 2\end{array}$ \\
\hline
\end{tabular}


Idaho National Laboratory

Page: 8 of 13

\begin{tabular}{c|ll}
$\begin{array}{c}\text { Software Acceptance Test Plan } \\
\text { for the Fukushima Daiichi } \\
\text { Accident Database }\end{array}$ & Identifier: & INL/EXT-12-24576 \\
Revision: & 0 \\
Effective Date: & January 18, 2012
\end{tabular}

\begin{tabular}{|c|c|c|}
\hline Parameter Data Chart & Fail & $\begin{array}{l}\text { Y-axis labels (numbers) not } \\
\text { fitting on charts depending on } \\
\text { the units selected. }\end{array}$ \\
\hline Report Creation & Pass & \\
\hline $\begin{array}{l}\text { Items included, events, artifacts, } \\
\text { charts }\end{array}$ & Pass & \\
\hline Organization & Pass & \\
\hline Report View & Pass & \\
\hline Security & Pass & \\
\hline $\begin{array}{l}\text { Navigation of non-public information } \\
\text { outside login not allowed }\end{array}$ & Pass & \\
\hline $\begin{array}{l}\text { Public access does not include } \\
\text { copyrighted or controlled information }\end{array}$ & Pass & \\
\hline Administrative Functions & Pass & \\
\hline Add contributor & Pass & \\
\hline Modify roles & Pass & \\
\hline Generate Report & Pass & \\
\hline Home Page Quick Navigation & Pass & \\
\hline Timeline & Fail & $\begin{array}{l}\text { Generally happens throughout } \\
\text { the application: GMT shows up } \\
\text { instead of local time if the } \\
\text { session is idle for } 20 \text { minutes. }\end{array}$ \\
\hline Recent additions & Pass & \\
\hline
\end{tabular}

Table 2 Quality Assurance Test performed on version 1.0.23

\begin{tabular}{|c|c|l|l|}
\hline \multicolumn{4}{|c|}{ Test of Fukushima Daiichi Accident Study Information Portal Revision 1.0.23 } \\
\hline Contributor Creation & Pass/Fail & Comment/Corrective Action & Image \\
\hline Artifact Creation & Pass & & \\
\hline media file links & Pass & & \\
\hline video & Pass & & \\
\hline spreadsheet & Pass & & \\
\hline image & Pass & & \\
\hline word document & Pass & & \\
\hline text & Pass & & \\
\hline pdf document & Pass & & Appx. 1 \\
\hline Parameter data & Pass & & Fig. 4 \\
& & $\begin{array}{l}\text { Added note to make it clear } \\
\text { when a parameter is not } \\
\text { associated to an event due to } \\
\text { time stamp from event being } \\
\text { required for parameter tracking }\end{array}$ & \\
\hline Component state & Pass & \\
\hline Event Creation & & & \\
\hline Review Creation & Pass & & \\
\hline
\end{tabular}


Idaho National Laboratory

Page: 9 of 13

\section{Software Acceptance Test Plan for the Fukushima Daiichi Accident Database}

\begin{tabular}{|c|c|c|c|}
\hline Review Artifact & Pass & & \\
\hline Review Event & Pass & & \\
\hline Timeline View & Pass & $\begin{array}{l}\text { A manual select radio button } \\
\text { was added to avoid confusion. }\end{array}$ & \\
\hline Navigation & Pass & & \\
\hline Login Functions & Pass & & \\
\hline Forgotten Password & Pass & & \\
\hline Chart Creation & Pass & & \\
\hline Component State Chart & Pass & $\begin{array}{l}\text { Timeline selection corrected to } \\
\text { allow a manual select radio } \\
\text { button to activate when the } \\
\text { calendar/clock entry is used. }\end{array}$ & \\
\hline Parameter Data Chart & Pass & $\begin{array}{l}\text { Corrected the problem of } \\
\text { numbers not fitting on charts } \\
\text { depending on the units } \\
\text { selected. }\end{array}$ & \\
\hline Report Creation & Pass & & \\
\hline $\begin{array}{l}\text { Items included, events, artifacts, } \\
\text { charts }\end{array}$ & Pass & & \\
\hline Organization & Pass & & \\
\hline Report View & Pass & & \\
\hline Security & Pass & & \\
\hline $\begin{array}{l}\text { Navigation of non-public information } \\
\text { outside login not allowed }\end{array}$ & Pass & & \\
\hline $\begin{array}{l}\text { Public access does not include } \\
\text { copyrighted or controlled information }\end{array}$ & Pass & & \\
\hline Administrative Functions & Pass & & \\
\hline Add contributor & Pass & & \\
\hline Modify roles & Pass & & \\
\hline Generate Report & Pass & & \\
\hline Home Page Quick Navigation & Pass & & \\
\hline Timeline & Pass & $\begin{array}{l}\text { The session times out at } 20 \\
\text { minutes and requires the user } \\
\text { to login again. This corrected } \\
\text { the reversion to GMT } \\
\text { throughout the application. }\end{array}$ & \\
\hline Recent additions & Pass & & \\
\hline
\end{tabular}




\begin{tabular}{|c|ll|}
\hline \multicolumn{2}{|l|}{ Page: 10 of 13} \\
\hline $\begin{array}{c}\text { Softwo National Laboratory } \\
\text { for the Fukushima Daiichi } \\
\text { Accident Database }\end{array}$ & Identifier: & INL/EXT-12-24576 \\
& Revision: & 0 \\
Effective Date: & January 18, 2012 \\
\hline
\end{tabular}

\section{FUKUSHIMA DAIICHI ACCIDENT STUDY INFORMATION PORTAL \\ Home \\ Help}

Welcome to the FukUshima DaIICHi Accident Study Information PoRTAL

Portal information is limited access.

Session timed out because of inactivity. New login required.

Please [Log In] or access the [Public] available view

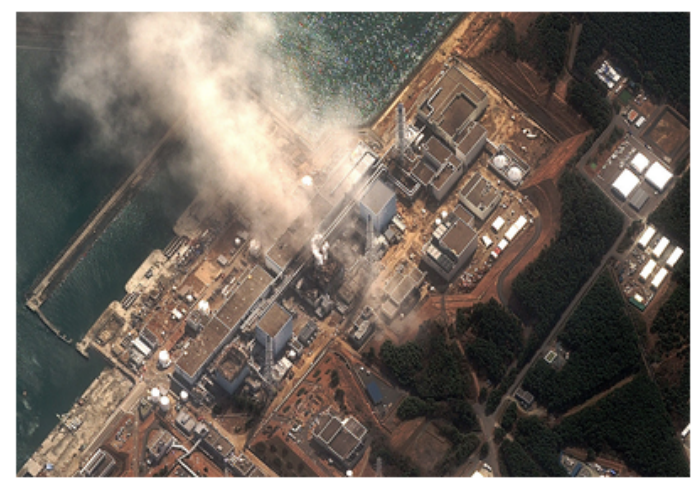

Figure 1 Session timed out due to 20 minutes inactivity 


\begin{tabular}{|c|ll|}
\hline \multicolumn{2}{|l|}{ Page: 11 of 13 } \\
\hline $\begin{array}{c}\text { Software Acceptance Test Plan } \\
\text { for the Fukushima Daiichi } \\
\text { Accident Database }\end{array}$ & Identifier: & INL/EXT-12-24576 \\
Revision: & 0 \\
Effective Date: & January 18, 2012 \\
\hline
\end{tabular}

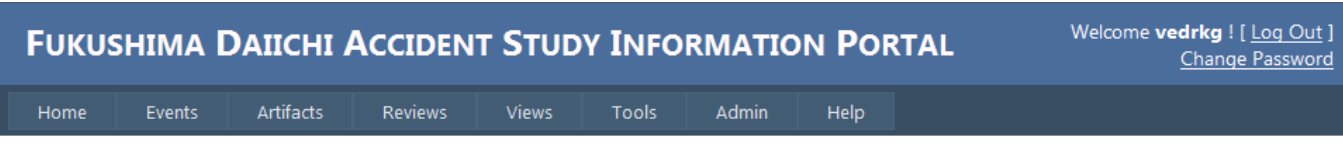

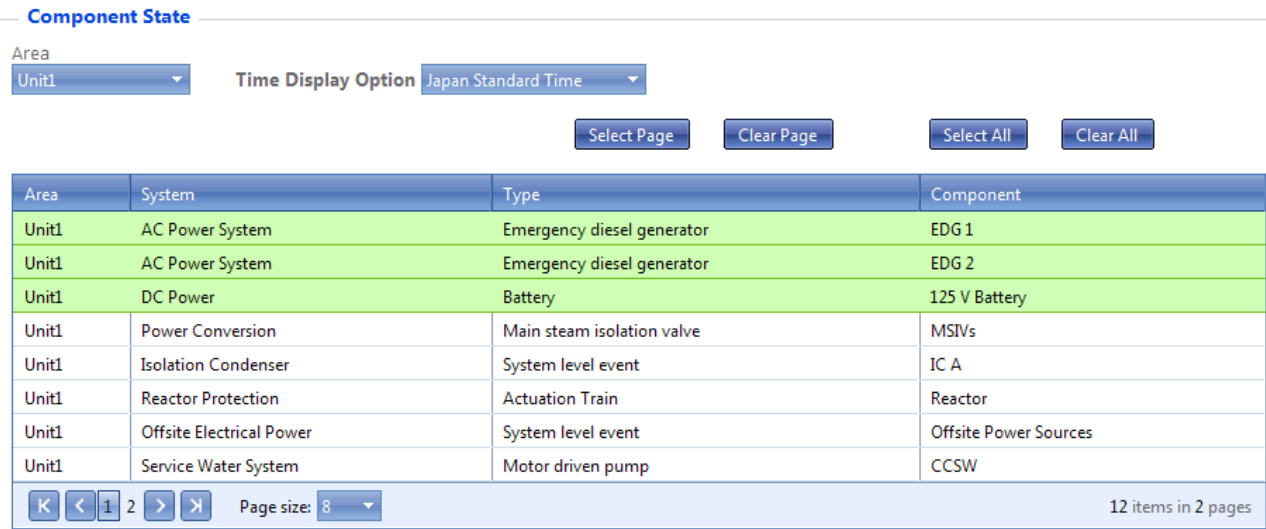

\begin{tabular}{|c|c|c|c|c|}
\hline \multirow{2}{*}{\multicolumn{2}{|c|}{$\begin{array}{l}\text { Chart Time Span (JST) } \\
\text { Starting Date/Time }\end{array}$}} & \multirow{2}{*}{\multicolumn{2}{|c|}{ Ending Date/Time }} & ○ $3 / 1112: 00+7$ days \\
\hline & & & & Oarthquake +7 days \\
\hline 3/11/2011 12:00 PM & \multirow[t]{3}{*}{ 㖆 Q } & 3/12/2011 12:00 PM & \multirow[t]{3}{*}{ 㖆 @ } & First data point +7 days \\
\hline & & & & O Earthquake to last data point \\
\hline & & & & O complete data span \\
\hline
\end{tabular}

Show Selected Values with Printable Chart

$\square$ Plot Comments $\square$ Current Date $\square$ Area $\square$ Component(s) $\square$ Time Span $\square$ Title Component State

\section{Preview Chart Print Chart Expot Data}

Component State

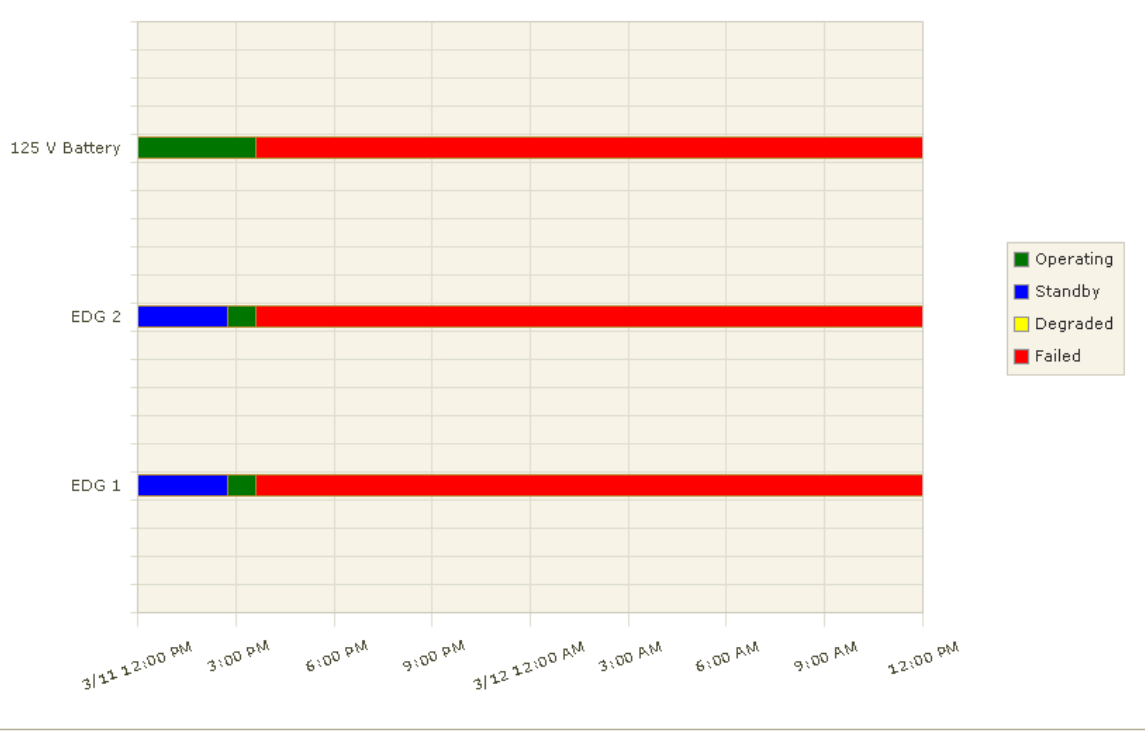

Figure 2 Timeline controlled component state chart that did not have the manual radio button 
Software Acceptance Test Plan

Identifier: INL/EXT-12-24576

for the Fukushima Daiichi

Accident Database

Revision: $\quad 0$

Effective Date: January 18, 2012

\section{FUKUSHIMA DAIICHI ACCIDENT STUDY INFORMATION PORTAL

\begin{tabular}{ll|l|l|l|l|l}
\hline Home Events & Artifacts & Reviews & Views & Tools & Admin & Help
\end{tabular}

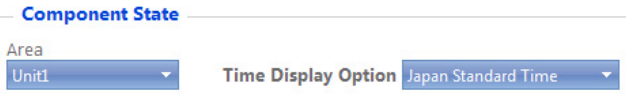

\begin{tabular}{|c|c|c|c|}
\hline Area & System & Type & Component \\
\hline Unit1 & AC Power System & Emergency diesel generator & EDG1 \\
\hline Unit1 & AC Power System & Emergency diesel generator & EDG 2 \\
\hline Unit1 & DC Power & Battery & $125 \mathrm{~V}$ Battery \\
\hline Unit1 & Power Conversion & Main steam isolation valve & MSINs \\
\hline Unit1 & Isolation Condenser & System level event & ICA \\
\hline Unit1 & Reactor Protection & Actuation Train & Reactor \\
\hline Unit1 & Offsite Electrical Power & System level event & Offsite Power Sources \\
\hline Unit1 & Service Water System & Motor driven pump & $\operatorname{ccs} w$ \\
\hline
\end{tabular}

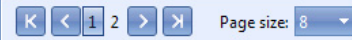

Chart Time Span (JST) Starting Date/Time

3/11/2011 12:00 PM 㘣 (Q) 3/11/2011 6:00 PM 㘣 ()

O Earthquake +7 days

O First data point +7 days

OEarthquake to last data point

O complete data span

- Set Manually

Show Selected Values with Printable Chart

\plot Comments $\square$ current Date $\square$ Area $\square$ component(s) $\square$ Time Span $\square$ Title Component State

\section{Preview Chart Print Chart Export Data}

\section{Component State}

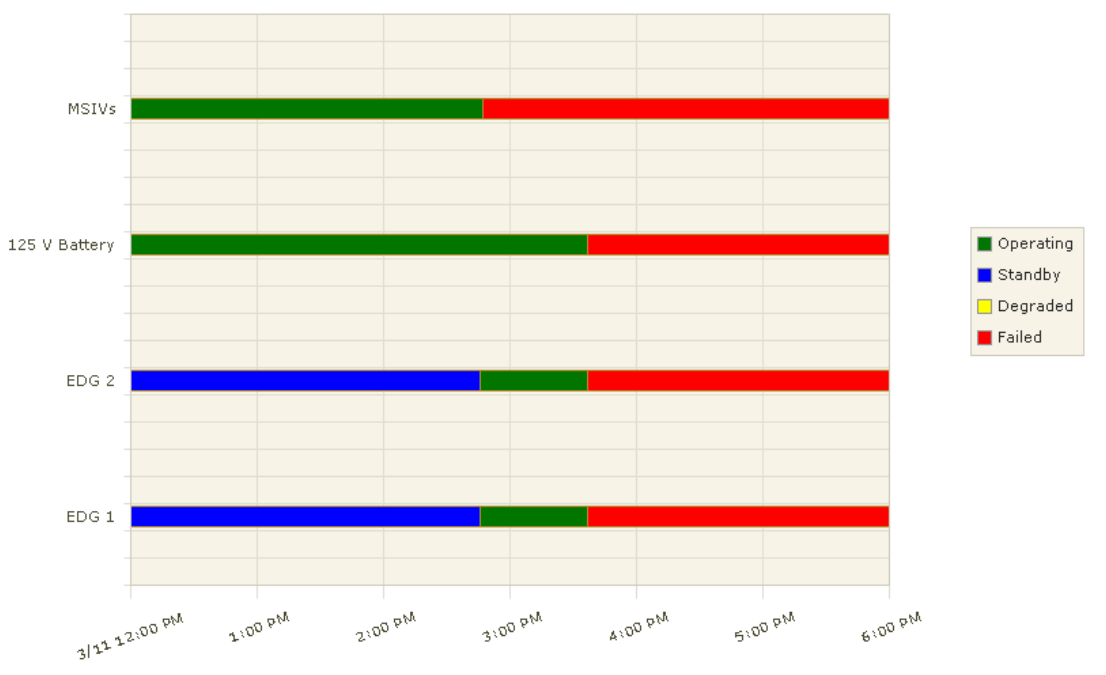

Figure 3 Component state chart with Set Manually radio button 


\begin{tabular}{|l|ll|}
\hline \multicolumn{2}{|l|}{ Page: 13 of 13} \\
\hline $\begin{array}{c}\text { Software Acceptance Test Plan } \\
\text { for the Fukushima Daiichi } \\
\text { Accident Database }\end{array}$ & Identifier: & INL/EXT-12-24576 \\
Revision: & Effective Date: & January 18, 2012 \\
\hline
\end{tabular}

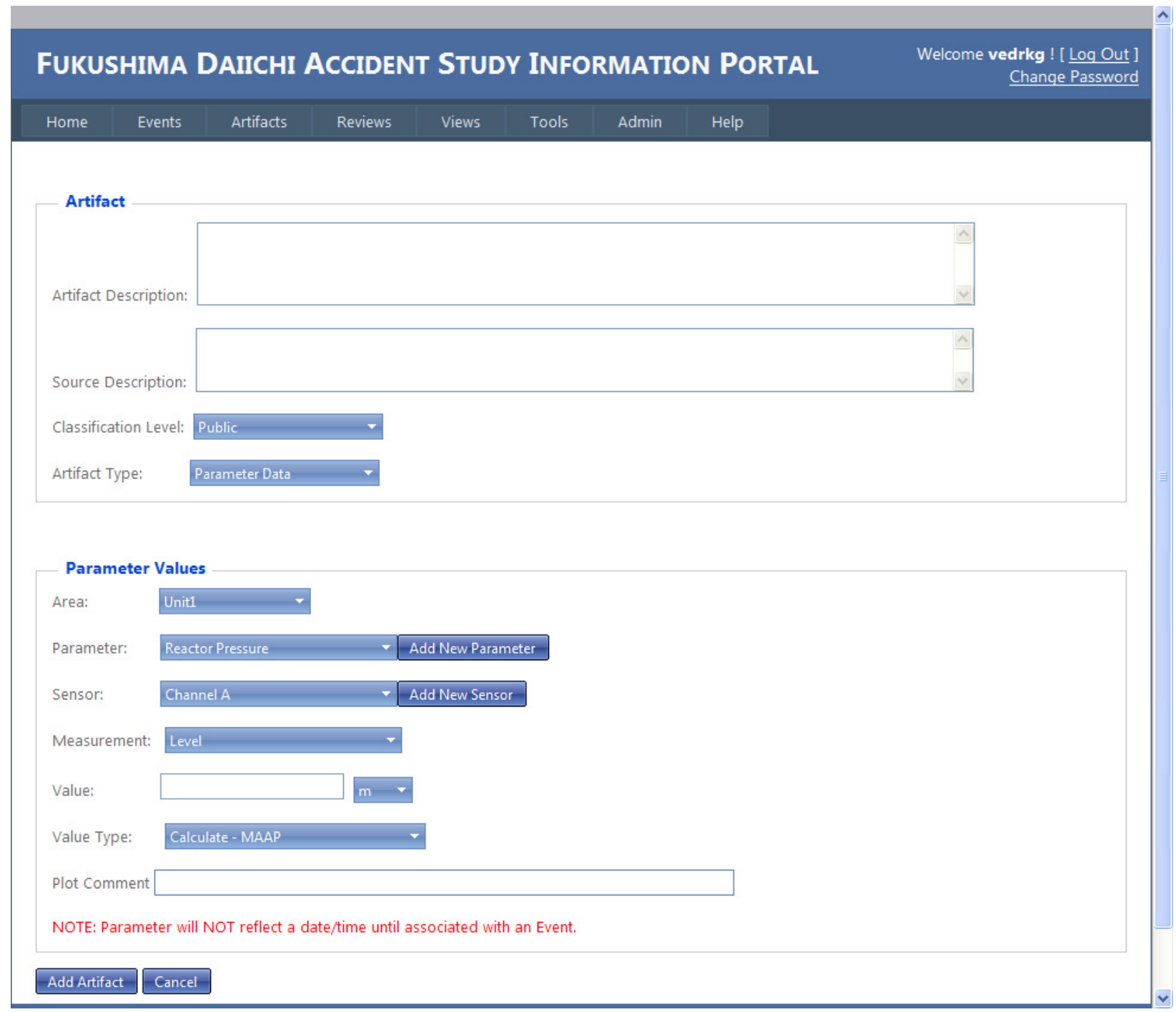

Figure 4 Red NOTE reminder that a parameter must be associated with an event before reflecting a date and time 